\title{
CARDIAC RHYTHM AND ATRIAL TRANSPORT FUNCTION AFTER SURGICAL ABLATION OF ATRIAL FIBRILLATION USING CRYOENERGY: PREDICTORS AND EFFECTIVENESS OF THE PROCEDURE
}

\author{
Martin Kolek*, Radim Brat \\ Department of Cardiac Surgery, University Hospital, Ostrava, Czech Republic \\ E-mail:kolek.martin@centrum.cz
}

Received: October 25, 2010; Accepted: February 23, 2010

Key words: Atrial fibrillation/Maze procedure/Cryoablation/Arrhythmia surgery/Atrial transport function

\begin{abstract}
Aim. The aim of this prospective study was to assess the presence of sinus rhythm and atrial transport function after surgical ablation of atrial fibrillation using cryoenergy, and to evaluate predictors of the success of the procedure.

Methods. Between January 2005 and September 2006, 100 consecutive patients underwent left atrial cryoablation as a concomitant surgical procedure (46 patients with paroxysmal or persistent atrial fibrillation and 54 with permanent atrial fibrillation). Mitral valve surgery was performed in $74 \%$. The mean and the median times of follow-up were $20 \pm 8.5$, and 24 months respectively. Atrial mechanical function was assessed by echocardiography.

Results. Sinus rhythm was achieved during the postoperative follow-up in $71-81 \%$ of patients - significantly more often in the group with paroxysmal and persistent atrial fibrillation (90-98\%), than patients with permanent atrial fibrillation prior to surgery $(51-65 \%)(p<0.002)$. At 12 and 24 months after the surgery, a total of $68.2 \%$ and $51.2 \%$ of the patients were free from atrial fibrillation; $73.9 \%$ and $60.7 \%$ of the patients from the paroxysmal and persistent atrial fibrillation group, and $60.3 \%$ and $37.7 \%$ of patients with permanent atrial fibrillation $(p=0.05)$. Five per cent of patients required postoperative permanent pacemaker implantation. An effective left and right atrial mechanical function was detected in $70-90 \%$, and $96-98 \%$ of patients with sinus rhythm respectively. The following circumstances were identified as negative predictors of the presence of sinus rhythm after the ablation procedure: growing diameter of the left atrium, the duration of atrial fibrillation and the severity of mitral and tricuspid regurgitation before surgery $(p<0.05)$. Restoration of the left atrial transport function was negatively predicted by the preoperative diameter of the left atrium, the presence of mitral valve stenosis and the severity of tricuspid regurgitation ( $p<0.05)$. A total of $95.4 \%$ of patients were free from stroke at one-year follow-up, and $94.1 \%$ at 2 years after surgery.

Conclusion. Stable sinus rhythm and effective left atrial transport function are the main factors resulting in decreased morbidity after successful ablation of atrial fibrillation. A careful post-operative follow-up of the patients and individualised treatment are necessary.
\end{abstract}

\section{INTRODUCTION}

Atrial fibrillation $(\mathrm{AF})$ is the most common sustained arrhythmia. Its prevalence among the adult population is about $1 \%$ and steadily rising ${ }^{1}$. The percentage of patients with AF significantly increases with age. We can diagnose $\mathrm{AF}$ in about $0.1 \%$ of adult patients younger than 55 years of age, the prevalence in patients over 60 years of age is about $3.8 \%$, and in patients above 80 years of age it reaches a level of $9 \%\left(\right.$ ref. $^{1-4}$ ). The AF attacks become more frequent with age, and the arrhythmia becomes permanent $t^{5}$. However, the "epidemic" occurrence of AF cannot be explained by the aging of the population only; a higher incidence is found even after correction for age, sex and predisposing conditions ${ }^{3}$. According to the EuroHeart Failure Survey, intermittent or permanent $\mathrm{AF}$ occurs in up to $45 \%$ of patients with heart failure ${ }^{6}$. Its prevalence depends on the severity of heart failure, and rises approximately from $5 \%$ in the NYHA I functional class up to $50 \%$ in NYHA IV class 7 . Up to $50 \%$ of patients undergoing mitral valve surgery are diagnosed with $\mathrm{AF}$ prior to the surgery ${ }^{8-11}$.
The presence of AF is associated with higher morbidity and mortality, conditioned by thromboembolic events, circulatory complications, development of tachyarrhythmic cardiomyopathy, as well as bleeding complications in the course of necessary anticoagulation therapy ${ }^{12,13}$. The increased risk of thromboembolism can be explained by loss of effective atrial contractions and subsequent blood stagnation in the left atrium, namely in its appendage, with formation of intracavital thrombi. The incidence of ischemic stroke in patients with $\mathrm{AF}$ is about $5 \%$ per year, which is 2 to 7 times higher than in patients with sinus rhythm (SR $)^{14}$. The mortality of patients with AF is about two times higher than in individuals with $\mathrm{SR}^{5,15}$.

The presently used modifications of surgical ablation techniques (for atrial fibrillation) are derived from the Cox-maze procedure ${ }^{16}$. Most of the incisions of the atrial wall performed in the past have been substituted with linear lesions with the use of different instruments using "alternative" sources of energy, such as cryoenergy, radiofrequency energy, microwaves, focused ultrasound or laser. The development of new surgical techniques was motivated by efforts to decrease the risk or periopera- 
tive and early postoperative complications of the original maze procedure while preservating its effectiveness at the same time. The basic principle of the procedure remains unchanged. The surgical ablation of AF is a routine procedure today and concomitant part of the spectrum of cardiosurgical techniques.

The aim of this prospective study was, on the basis of a two-year follow-up of a group of patients, to assess the effect of surgical ablation of AF using cryoenergy (carried out as a concomitant cardiosurgical procedure) on attainment and maintenance of SR and atrial transport function, and to evaluate predictors of the procedural success.

\section{PATIENTS AND METHODS}

Between January 2005 and September 2006, a total of 100 consecutive patients underwent surgical ablation of AF using cryoenergy as a part of combined cardiac operation. All procedures were performed at Department of Cardiac Surgery, University Hospital Ostrava, Czech Republic. The basic characteristic of the group, including the division into paroxysmal + persistent and permanent AF subgroups, is shown in Table 1. The mean age of the patients was 67.6 years (range, 50 to 82 years); there was no difference in the mean age between men and women. The number of men was slightly higher than the number of women ( 59 men, 41 women). Forty-six patients suffered from paroxysmal or persistent AF and fifty-four patients from permanent AF prior to the surgery. The patients with permanent AF had, compared to patients with paroxysmal or persistent AF, a significantly larger left atrium $(51.4 \pm 6.8 \mathrm{~mm}$ vs $46.7 \pm 5.3 \mathrm{~mm}, \mathrm{p}<0.001)$ and a more severe tricuspid regurgitation (2.3/4 grade vs $1.5 / 4$ grade, $\mathrm{p}<0.001$ ), a mitral stenosis was non-significantly more frequent.

The spectrum of primarily indicated cardiosurgical procedures is shown in Table 2 . Valve surgery clearly prevailed - performed isolated or combined with coronary artery bypass graft (CABG) surgery. The most common (74 patients) was the mitral valve surgery (for mitral regurgitation or combined stenosis and regurgitation). The isolated mitral valve repair was carried out in 5 patients, and as a part of a combined procedure in 47 patients. An isolated replacement of the mitral valve with a mechanical or biological prosthesis was realized in 6 patients, the remaining 16 patients underwent this procedure as a part of a complex surgery.

The patients with permanent AF, compared to the patients with paroxysmal or persistent AF, had a non-

Table 1. Preoperative patient characteristics.

\begin{tabular}{|c|c|c|c|c|}
\hline Variable & Whole AF group & $\begin{array}{l}\text { Paroxysmal + per- } \\
\text { sistent AF group }\end{array}$ & $\begin{array}{l}\text { Permanent } \mathrm{AF} \\
\text { group }\end{array}$ & $\mathrm{p}$ value \\
\hline Group size (n, \%) & $100(100 \%)$ & $46(46 \%)$ & $54(54 \%)$ & \\
\hline Female (\%) & 41 & 41.3 & 40.7 & NS \\
\hline $\begin{array}{l}\text { Age } \\
\text { (yrs, mean, SD, range) }\end{array}$ & $\begin{array}{c}67.6 \pm 7.2 \\
(50-82)\end{array}$ & $\begin{array}{c}67.9 \pm 7.3 \\
(50-82)\end{array}$ & $\begin{array}{c}67.4 \pm 7.2 \\
(52-82)\end{array}$ & NS \\
\hline $\begin{array}{l}\text { LA dimension } \\
\text { (mm, mean, SD, range) }\end{array}$ & $\begin{array}{l}49.2 \pm 6.6 \\
(38-80)\end{array}$ & $\begin{array}{c}46.7 \pm 5.3 \\
(38-60)\end{array}$ & $\begin{array}{l}51.4 \pm 6.8 \\
(42-80)\end{array}$ & $<0.001 *$ \\
\hline $\begin{array}{l}\text { LVEDD } \\
\text { (mm, mean, SD, range) }\end{array}$ & $\begin{array}{c}54.2 \pm 7.3 \\
(38-74)\end{array}$ & $\begin{array}{c}53.9 \pm 6.9 \\
(38-67)\end{array}$ & $\begin{array}{c}54.4 \pm 7.7 \\
(39-74)\end{array}$ & NS \\
\hline $\begin{array}{l}\text { LVESD } \\
\text { (mm, mean, SD, range) }\end{array}$ & $\begin{array}{l}40.0 \pm 8.0 \\
(21-62)\end{array}$ & $\begin{array}{l}39.5 \pm 8.3 \\
(21-58)\end{array}$ & $\begin{array}{l}40.5 \pm 7.8 \\
(25-62)\end{array}$ & NS \\
\hline $\begin{array}{l}\mathrm{LVEF} \\
(\%, \text { mean, SD, range })\end{array}$ & $\begin{array}{l}49.1 \pm 11.3 \\
(22.5-78)\end{array}$ & $\begin{array}{l}50.0 \pm 12.9 \\
(25-78)\end{array}$ & $\begin{array}{l}48.2 \pm 9.8 \\
(22.5-70)\end{array}$ & NS \\
\hline $\begin{array}{l}\text { Mitral stenosis } \\
(\mathrm{n}, \%)\end{array}$ & $12(12 \%)$ & $4(8.7 \%)$ & $8(14.8 \%)$ & NS \\
\hline $\begin{array}{l}\text { Mitral regurgitation } \\
\left(\text { severity }^{+}, \text {mean, SD, range) }\right.\end{array}$ & $\begin{array}{c}2.6 \pm 1.1 \\
(0-4)\end{array}$ & $\begin{array}{l}2.4 \pm 1.2 \\
(0-4)\end{array}$ & $\begin{array}{l}2.7 \pm 1.1 \\
(0-4)\end{array}$ & NS \\
\hline $\begin{array}{l}\text { Tricuspid regurgitation } \\
\text { (severity }^{+} \text {, mean, SD, range) }\end{array}$ & $\begin{array}{l}1.9 \pm 1.0 \\
(0-4)\end{array}$ & $\begin{array}{l}1.5 \pm 1.1 \\
(0-4)\end{array}$ & $\begin{array}{c}2.3 \pm 0.9 \\
(1-4)\end{array}$ & $<0.001 *$ \\
\hline
\end{tabular}

$\mathrm{AF}=$ atrial fibrillation, $\mathrm{LA}=$ left atrium, $\mathrm{LV}=$ left ventricle, $\mathrm{LVEDD}=$ left ventricular end diastolic diameter, $\mathrm{LVEF}$ $=$ left ventricular ejection fraction, LVESD = left ventricular end systolic diameter

+ semiquantitative assessment of the valve regurgitation severity - four-grade scale, * statistically significant, NS - non significant 


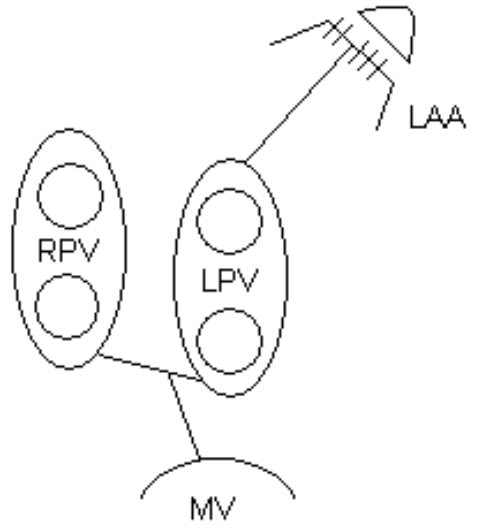

Fig. 1. Schematic illustration of the current ablation procedure.

LAA $=1$ eft atrial appendage, $\mathrm{LPV}=1 \mathrm{eft}$ pulmonary veins, $\mathrm{MV}=$ mitral valve, $\mathrm{RPV}=$ right pulmonary veins

significantly higher frequency of mitral valve surgery ( 44 vs 30, $\mathrm{p}=0.07$ ) and less frequent isolated CABG (also non-significantly, 5 vs $10, \mathrm{p}=0.08$ ); non-significantly more frequent were combined procedures (valve + CABG surgery, 22 vs 12).

\section{Surgical technique}

The ablation procedure was performed with a flexible cryoprobe (SurgiFrost, CryoCath/Endocare Inc.), using an argon-based cooling system which enables to reach the temperature of $-160{ }^{\circ} \mathrm{C}$. Linear lesions were realized epicardially or endocavitally. When the left atrium was not opened, the cryolesions were done epicardially (with the exception of the line from the base of the left atrial appendage to the left pulmonary veins orifice, where we preferred endocavital approach - after resection of the left atrial appendage). When the left atrium was opened (in mitral valve surgery), endocavital lesions were preferred.

The procedure (Fig. 1) consisted of a circular lesion around the left pulmonary vein orifices, resection of the left atrial appendage, endocavital cryoablation from the base of the appendage up to the orifice of the left pulmonary veins, suture of the base of the appendage. Circumferential lesion around the right pulmonary vein orifices was then carried out (if the atrium was opened, the ventral portion of this lesion corresponded to the incision of the left atrium); followed by cryolesions on the posterior wall of the left atrium connecting the left and right pulmonary veins and lesion from the mitral valve annulus to the orifice of the left pulmonary veins.

\section{Postoperative care and follow-up}

\section{Anticoagulation therapy}

All patients after valve surgery received anticoagulation therapy (warfarin). The anticoagulation was also indicated in patients following isolated $\mathrm{CABG}$ with preoperatively present permanent $\mathrm{AF}$, in patients following isolated $\mathrm{CABG}$ with persistent AF lasting at the time of
Table 2. Surgical procedures.

\begin{tabular}{|c|c|}
\hline Procedure & $\begin{array}{c}\text { No. } \\
(\mathrm{n}=100)\end{array}$ \\
\hline MV repair/replacement & 11 \\
\hline+ TV repair & 15 \\
\hline+ TV repair + ASD $/ \mathrm{PFO}$ & 5 \\
\hline$+\mathrm{TV}$ repair $+\mathrm{AV}$ replacement & 4 \\
\hline$+\mathrm{TV}$ repair $+\mathrm{CABG}$ & 8 \\
\hline$+\mathrm{AV}$ replacement & 1 \\
\hline$+\mathrm{AV}$ replacement + septal myectomy & 1 \\
\hline$+\mathrm{AV}$ replacement $+\mathrm{CABG}$ & 3 \\
\hline+ Bentall & 2 \\
\hline$+\mathrm{CABG}$ & 18 \\
\hline$+\mathrm{CABG}+\mathrm{ASD} / \mathrm{PFO}$ & 1 \\
\hline$+\mathrm{CABG}+\mathrm{CEA}$ & 1 \\
\hline$+\mathrm{ASD} / \mathrm{PFO}$ & 3 \\
\hline + LA thrombus extirpation & 1 \\
\hline TV repair + ASD & 1 \\
\hline AV replacement & 4 \\
\hline $\begin{array}{l}\text { AV replacement + septal myectomy + } \\
\text { CEA }\end{array}$ & 1 \\
\hline AV replacement + CABG & 2 \\
\hline Bentall & 1 \\
\hline Bentall + CABG & 1 \\
\hline $\mathrm{CABG}$ & 14 \\
\hline $\mathrm{CABG}+\mathrm{ASD} / \mathrm{PFO}$ & 1 \\
\hline $\begin{array}{l}\text { Pacemaker electrode extraction } \\
\text { (endocarditis) }\end{array}$ & 1 \\
\hline
\end{tabular}

$\mathrm{ASD}=$ atrial septal defect, $\mathrm{AV}=$ aortic valve, Bentall $=$ Bentall operation, CABG = coronary artery bypass grafting, CEA = carotid endarterectomy, LA = left atrium, $\mathrm{MV}=$ mitral valve, $\mathrm{PFO}=$ patent foramen ovale, $\mathrm{TV}=$ tricuspid valve

surgery for a time period exceeding 48 hours, or in patients with postoperative AF lasting more than 48 hours.

The therapeutic levels of International Normalized Ratio (INR) were defined in the following way: INR 2.53.5 following a valve replacement, INR 2.5-3 following a mitral or tricuspid valve plasty, INR 2-3 in patients with $\mathrm{AF}$, with no valvular surgery.

The anticoagulation was administered for a period of at least 3 months, after that individually, depending on the presence of risk factors of arterial embolisation, current heart rhythm and detection of effective left atrial transport function (absence of effective left atrial contractions in patients with SR was an indication for prolonged anticoagulation therapy). Patients with mechanical valve prosthesis were, of course, anticoagulated permanently.

\section{Antiarrhythmics}

Antiarrhythmic medication after surgery was provided for all patients who underwent left atrial cryoablation for indications of persistent or permanent $\mathrm{AF}$, and further 
for all patients with postoperative recurrence of AF (or other supraventricular tachyarrhythmia). Amiodarone was the drug of choice; other antiarrhythmics were administered in case of contraindication or in cases when adverse events were observed. The total saturation dose of amiodarone was 10 grams.

The antiarrhythmic therapy was discontinued at 6 months postoperatively - in case of a stable SR, verified with a 24-hour Holter ECG monitoring.

\section{Postoperative follow-up}

The patients were contacted for medical examinations at $1,3.5,6,12,18$ and 24 months following the surgery. The mean time of postoperative follow-up was $20 \pm 8.5$ months; the median follow-up period was 24 months. The medical examination consisted of an evaluation of the heart rhythm (actual, in the meantime between the examinations and during 24-hour Holter ECG monitoring), evaluation and possible modification of medication, decision concerning possible direct current (DC) cardioversion and assessment of the need for permanent pacemaker implantation and the occurrence of complications, especially embolic.

Holter ECG monitoring was repeated in 6-month intervals. Any episode lasting more than 30 seconds was considered a recurrence of AF (continuous arrhythmia).

The decision on DC cardioversion for recurrence of the atrial fibrillation was done on an individual basis. We took into consideration mainly the type and duration of the atrial fibrillation before the surgery, the size of the left atrium and the number of recurrences, or cardioversions in the postoperative period. Standard treatment consisted of applying synchronised biphasic shocks.

For the purpose of assessment of the "freedom from atrial fibrillation" parameter (or more precisely "freedom from atrial tachyarrhythmia"), we carried out a detailed analysis of the development of the heart rhythm in individual patients. All documented recurrences of AF (as well as all the other supraventricular tachyarrhythmias - atrial flutter, supraventricular tachycardia) were taken into account during the analysis, including attacks in the interval between the planned medical examinations and paroxysms detected using 24-hour ECG Holter monitoring, with spontaneous, pharmacological or electric version to the SR. The duration of the AF attacks had to exceed a period of 30 seconds or the duration of AF was unclear.

Left and right atrial transport function was assessed with echocardiography - pulsed-wave Doppler examination of the diastolic mitral and tricuspid flow (apical fourchamber view with a sample volume positioned between the tips of the mitral or tricuspid leaflets). Atrial mechanical activity was considered present if an atrial filling (A) wave was detected. Peak velocity of the A-wave $\geq 25 \mathrm{~cm} / \mathrm{s}$ (transmitral inflow) and peak A-wave velocity $\geq 10 \mathrm{~cm} / \mathrm{s}$ (transtricuspid inflow) were considered a haemodynamically effective contraction. Both values were defined arbitrarily. This method of atrial transport function evaluation was chosen because of its simplicity and repeatability in clinical practice during routine echocardiographic examinations.

During the examinations we also followed the dynamics of the left atrium size and the end-diastolic and end-systolic diameter of the left ventricle (measured with two-dimensional echocardiography in parasternal long axis). Analogously, the development of left ventricular systolic function over time was monitored; its ejection fraction was obtained by planimetry (Simpson method). The severity of mitral and tricuspid regurgitation was assessed only semiquantitatively (four-grade scale).

Echocardiography was carried out with the use of a Hewlett-Packard Sonos 5500 machine.

On the basis of the acquired data, we tried to determine clinical and echocardiographic predictors of a stable SR and effective left atrial transport function after surgical ablation of AF.

\section{Statistical analysis}

Basic statistical characteristics (mean value, standard deviation, median, interval, absolute and relative frequency) were used to describe the group. For the analysis of the basic parameters in the subgroups, paroxysmal + persistent vs permanent $\mathrm{AF}$, we used, in relation to the type of parameters, the following statistical tests $-\chi^{2}$ test, two-sample t-test and nonparametric two-sample Wilcoxon test. The comparison of the presence of SR and atrial transport function in the subgroups with paroxysmal + persistent vs permanent AF was done using $\chi^{2}$ test and Fisher's exact test. The assessment of "freedom from AF" and "freedom from stroke" parameters was carried out by Kaplan-Meier analysis; to compare the curves, the logrank test was used. To assess the predictors of reaching the sinus rhythm and the predictors of the left atrial transport function, the nonparametric two-sample Wilcoxon test, $\chi^{2}$ test, Fisher's exact test and a two-sample t-test were used. Evaluation of the development of echocardiographic parameters was carried out using analysis of variance (ANOVA), and subsequently also by the Bonferroni test; the relation of these parameters in the subgroups paroxysmal + persistent vs permanent AF in the course of medical examinations was assessed with a two sample t-test. A $p$ value less than 0.05 was considered statistically significant. Statistical analysis was performed with Stata 9 (StataCorp LP, College Station, TX).

\section{RESULTS}

\section{Heart rhythm}

A total of 34 (34\%) patients had stable SR in the course of hospitalization (from the end of the operation to discharge from the hospital or death). At least one recurrence of AF was detected in 63 (63\%) of the patients, and at least one episode of atrial flutter or atrial tachycardia was detected in 3 (3\%) of patients. As expected, we encountered worse results in the group of patients with permanent AF, where the level of patients with stable SR in the course of hospitalisation reached only $24.1 \%$ 


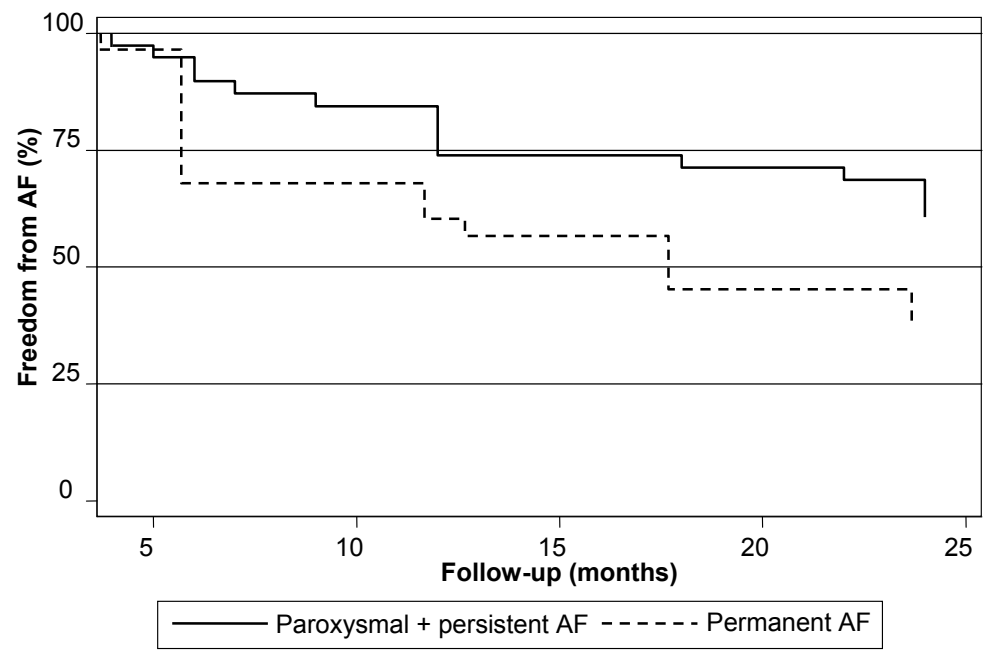

Fig. 2. Freedom from atrial fibrillation.

$\mathrm{AF}=$ atrial fibrillation

(compared to $45.7 \%$ in the subgroup of patients with paroxysmal + persistent AF).

A total of 68 patients were discharged with SR ( $76.4 \%$ - in relation to the number of surviving patients) (Table 3). We observed a statistically more frequent SR in patients with paroxysmal and persistent $\mathrm{AF}$, versus patients with permanent $\mathrm{AF}-88.1 \%$ vs $66 \%(\mathrm{p}=0.01)$. Eighteen patients underwent a successful DC cardioversion of AF during hospitalisation.

The occurrence of SR in the course of the two-year follow-up in patients after surgical ablation of the AF (during the planned medical examinations at 1, 3.5, 6, 12, 18 and 24 months following the surgery) was $71-81 \%$ (Table 3). SR was observed significantly more often in patients referred for ablation for paroxysmal and persistent $\mathrm{AF}(90-98 \%)$ than in patients with permanent $\mathrm{AF}$ prior to the surgery $(51-65 \%)(p<0.002)$.

Using the Kaplan-Meier analysis, we determined a parameter "freedom from atrial fibrillation", encompassing late recurrences of AF (or other supraventricular tachyarrhythmia). The starting point was the heart rhythm at 3.5 months after the surgery. "Freedom from AF" was $68.2 \%$ at 1 year and $51.2 \%$ at 2 years after surgery. When paroxysmal + persistent AF group versus permanent $\mathrm{AF}$ group were compared, the difference was on the border of statistical significance ( $73.9 \%$ and $60.7 \%$ vs $60.3 \%$ and $37.7 \%, p=0.05$ ) (Fig. 2).

Table 3. Heart rhythm.

\begin{tabular}{|c|c|c|c|c|c|c|c|c|}
\hline \multirow[t]{2}{*}{ Follow-up } & \multirow[t]{2}{*}{ Rhythm } & \multicolumn{2}{|c|}{ Whole AF group } & \multicolumn{2}{|c|}{$\begin{array}{c}\text { Paroxysmal } \\
+ \text { persistent AF group }\end{array}$} & \multicolumn{2}{|c|}{ Permanent AF group } & \multirow[t]{2}{*}{$\mathrm{p}$ value } \\
\hline & & No. & $\%$ & No. & $\%$ & No. & $\%$ & \\
\hline \multirow[t]{2}{*}{ Dismission } & SR & 68 & 76.4 & 37 & 88.1 & 31 & 66.0 & \multirow{2}{*}{$0.01 *$} \\
\hline & $\mathrm{n}$ & 89 & 100.0 & 42 & 100.0 & 47 & 100.0 & \\
\hline \multirow[t]{2}{*}{1 month } & SR & 63 & 70.8 & 39 & 92.9 & 24 & 51.1 & \multirow{2}{*}{$<0.001$ * } \\
\hline & $\mathrm{n}$ & 89 & 100.0 & 42 & 100.0 & 47 & 100.0 & \\
\hline \multirow{2}{*}{3.5 months } & SR & 67 & 79.8 & 39 & 97.5 & 28 & 63.6 & \multirow{2}{*}{$<0.001$ * } \\
\hline & $\mathrm{n}$ & 84 & 100.0 & 40 & 100.0 & 44 & 100.0 & \\
\hline \multirow[t]{2}{*}{6 months } & SR & 65 & 77.4 & 38 & 95.0 & 27 & 61.4 & \multirow{2}{*}{$<0.001$ * } \\
\hline & $\mathrm{n}$ & 84 & 100.0 & 40 & 100.0 & 44 & 100.0 & \\
\hline \multirow[t]{2}{*}{12 months } & SR & 61 & 75.3 & 35 & 89.7 & 26 & 61.9 & \multirow{2}{*}{$0.005 *$} \\
\hline & $\mathrm{n}$ & 81 & 100.0 & 39 & 100.0 & 42 & 100.0 & \\
\hline \multirow[t]{2}{*}{18 months } & SR & 64 & 81.0 & 38 & 97.4 & 26 & 65.0 & \multirow{2}{*}{$<0.001$ * } \\
\hline & $\mathrm{n}$ & 79 & 100.0 & 39 & 100.0 & 40 & 100.0 & \\
\hline \multirow[t]{2}{*}{24 months } & SR & 57 & 73.1 & 35 & 89.7 & 22 & 56.4 & \multirow{2}{*}{$0.002 *$} \\
\hline & $\mathrm{n}$ & 78 & 100.0 & 39 & 100.0 & 39 & 100.0 & \\
\hline
\end{tabular}

$\mathrm{AF}=$ atrial fibrillation, $\mathrm{SR}=$ sinus rhythm

* statistically significant 
Table 4. Holter ECG monitoring.

\begin{tabular}{|c|c|c|c|c|c|c|}
\hline \multirow{2}{*}{ Follow-up } & \multicolumn{2}{|c|}{ Permanent SR } & \multicolumn{2}{c|}{$\begin{array}{c}\text { Permanent AF or another } \\
\text { SV tachyarrhythmia * }\end{array}$} & \multicolumn{2}{c|}{$\begin{array}{c}\text { SR with paroxysms of AF or } \\
\text { another SV tachyarrhythmia }\end{array}$} \\
\cline { 2 - 7 } & No. & $\%$ & No. & $\%$ & No. & $\%$ \\
\hline 6 months & 59 & 70.2 & 18 & 21.4 & 5 & 6.0 \\
\hline 12 months & 50 & 61.7 & 20 & 24.7 & 9 & 11.1 \\
\hline 18 months & 45 & 57.0 & 15 & 19.0 & 16 & 20.3 \\
\hline 24 months & 41 & 52.6 & 19 & 24.4 & 16 & 20.5 \\
\hline
\end{tabular}

$\mathrm{AF}=$ atrial fibrillation, $\mathrm{SR}=$ sinus rhythm, * another supraventricular tachyarrhythmia (atrial flutter, atrial tachycardia)

Table 5. Direct current cardioversion.

\begin{tabular}{|l|c|c|c|c|}
\hline \multirow{2}{*}{ Follow-up } & \multicolumn{2}{|c|}{$\begin{array}{c}\text { DC cardioversion } \\
\text { whole AF group }\end{array}$} & $\begin{array}{c}\text { DC cardioversion } \\
\text { permanent AF group }\end{array}$ & $\begin{array}{c}\text { SR restored } \\
\text { whole AF group }\end{array}$ \\
\cline { 2 - 5 } & No. & $\%$ & No. & No. \\
\hline Dismission - 1 month & 15 & 16.8 & 13 & 14 \\
\hline Month 2-6 & 15 & 17.9 & 12 & 14 \\
\hline Month 7-12 & 6 & 7.4 & 2 & 6 \\
\hline Month 13-18 & 4 & 5.1 & 2 & 4 \\
\hline Month 19-24 & 4 & 5.1 & 3 & 3 \\
\hline
\end{tabular}

$\mathrm{AF}=$ atrial fibrillation, $\mathrm{DC}$ cardioversion $=$ direct current cardioversion, $\mathrm{SR}=$ sinus rhythm

When we took into consideration the recurrences of $\mathrm{AF}$ (or other supraventricular tachyarrhythmia) captured only at the time of planned out-patient examination, we found the following: "freedom from $\mathrm{AF}^{\text {" }}$ at one-year follow-up - $81.8 \%$ (whole group), $89.5 \%$ (paroxysmal and persistent $\mathrm{AF}$ group), $71.1 \%$ (permanent $\mathrm{AF}$ group), at two-year follow-up - $72.6 \%$ (whole group), $81.6 \%$ (paroxysmal and persistent AF group) and 59.9\% (permanent AF group); statistically significant difference between the curves for paroxysmal and persistent $\mathrm{AF}$ versus permanent $\mathrm{AF}(\mathrm{p}=0.04)$.

Holter ECG monitoring was carried out during the follow-up examinations in $97.2 \%$ of the patients. The results are presented in Table 4. The prevalence of stable SR without paroxysms of supraventricular tachyarrhythmias decreased over time (elapsed from the operation), in parallel with the rise in detection of recurrent, mostly asymptomatic episodes of supraventricular tachyarrhythmias - in the course of clearly prevailing sinus rhythm, lasting several seconds, several minutes or, exceptionally, several hours. This occurrence was most probably associated with a gradual decrease in antiarrhythmic medication in patients with seemingly stable SR (in accordance with the Study protocol). The prevalence of asymptomatic AF episodes during standard medical follow-up, and also with the use of 24-hour Holter ECG monitoring, was certainly significantly underestimated.
We preferred an active approach to prophylaxis and treatment of AF recurrences. Amiodarone, the antiarrhythmic drug of choice, was administered to $82 \%$ of all patients at the time of discharge. There was no significant difference between the groups referred for surgical ablation for paroxysmal + persistent or permanent $\mathrm{AF}$ - $83.3 \%$ and $80.9 \%$ (Fig. 3). The group of atrioventricular-nodal-blocking agents included beta-blockers, calciumchannel blockers (verapamil and diltiazem) and digoxin, administered individually, i.e. without combination with antiarrhythmics from Class I and III (Vaughan-Williams classification). Fig. 3 clearly shows, that AV-nodalblocking agents were used very sporadically at the time of discharge and the same applied to sotalol. It was also very rare to leave the patient with any medication that did not affect the heart rhythm in any way.

Antiarrhythmic medication of Class IC and III was given for 6 months after the operation (if there was no reason for earlier discontinuing it, or, on the contrary, to continue the therapy). In the case of amiodarone, it was necessary to continue treatment in $44.4 \%, 38 \%$ and $34.6 \%$ of all patients $(38.5 \%, 33.3 \%$ and $28.2 \%$ of patients with paroxysmal + persistent $\mathrm{AF}$, and $50 \%, 42.5 \%$ and $41 \%$ of patients with originally permanent AF) at 12,18 and 24 months after the surgery (Fig. 3). In other words, patients in the permanent AF group, six months after surgery, had more frequently to prolong treatment with amiodarone (or it was repeatedly administered). The main 


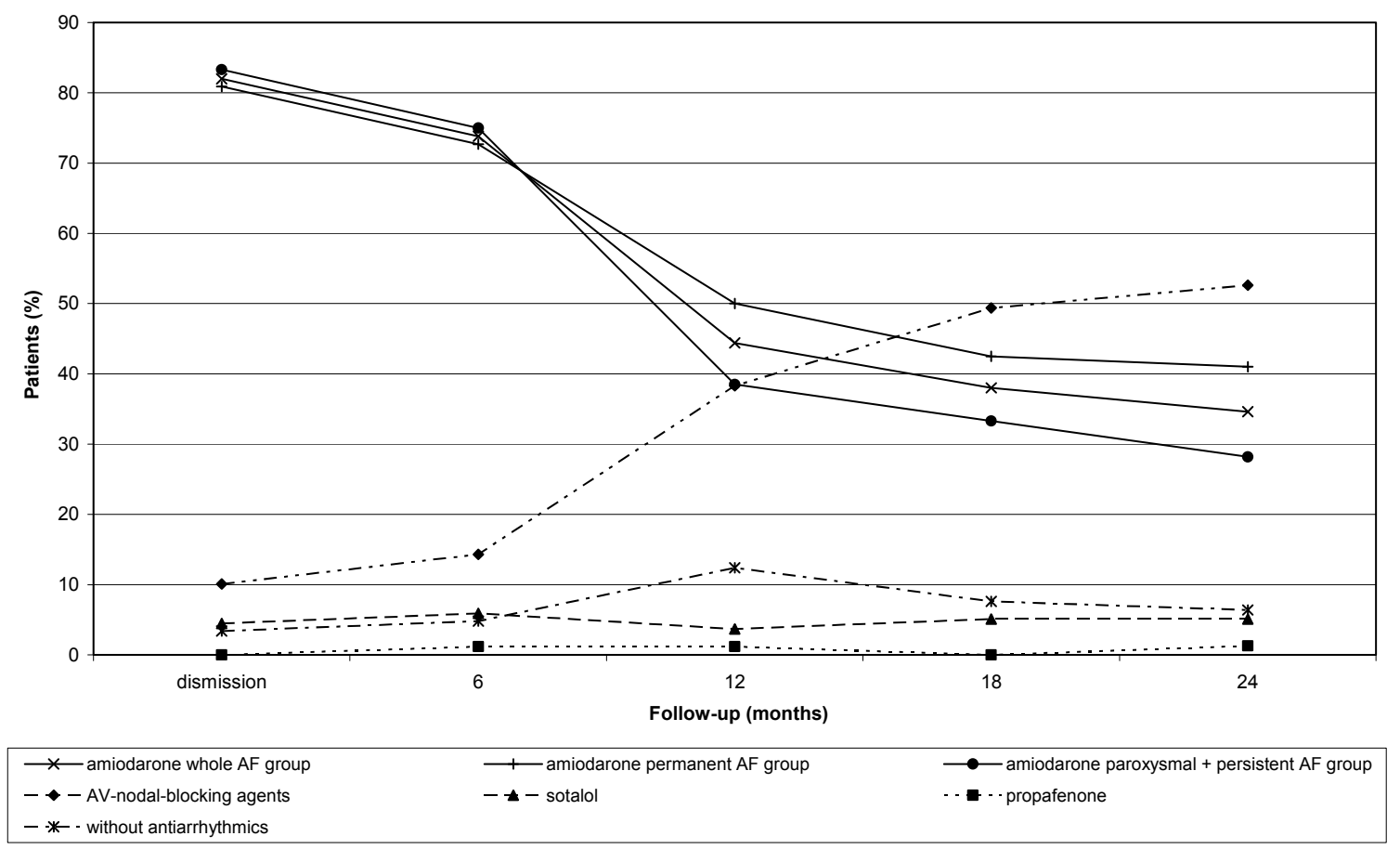

Fig. 3. Antiarrhythmic medication.

$\mathrm{AF}=$ atrial fibrillation, $\mathrm{AV}=$ atrioventricular $(\mathrm{AV}$-nodal-blocking agents $=$ beta-blockers, calcium-channel blockers (verapamil, diltiazem), digoxin)

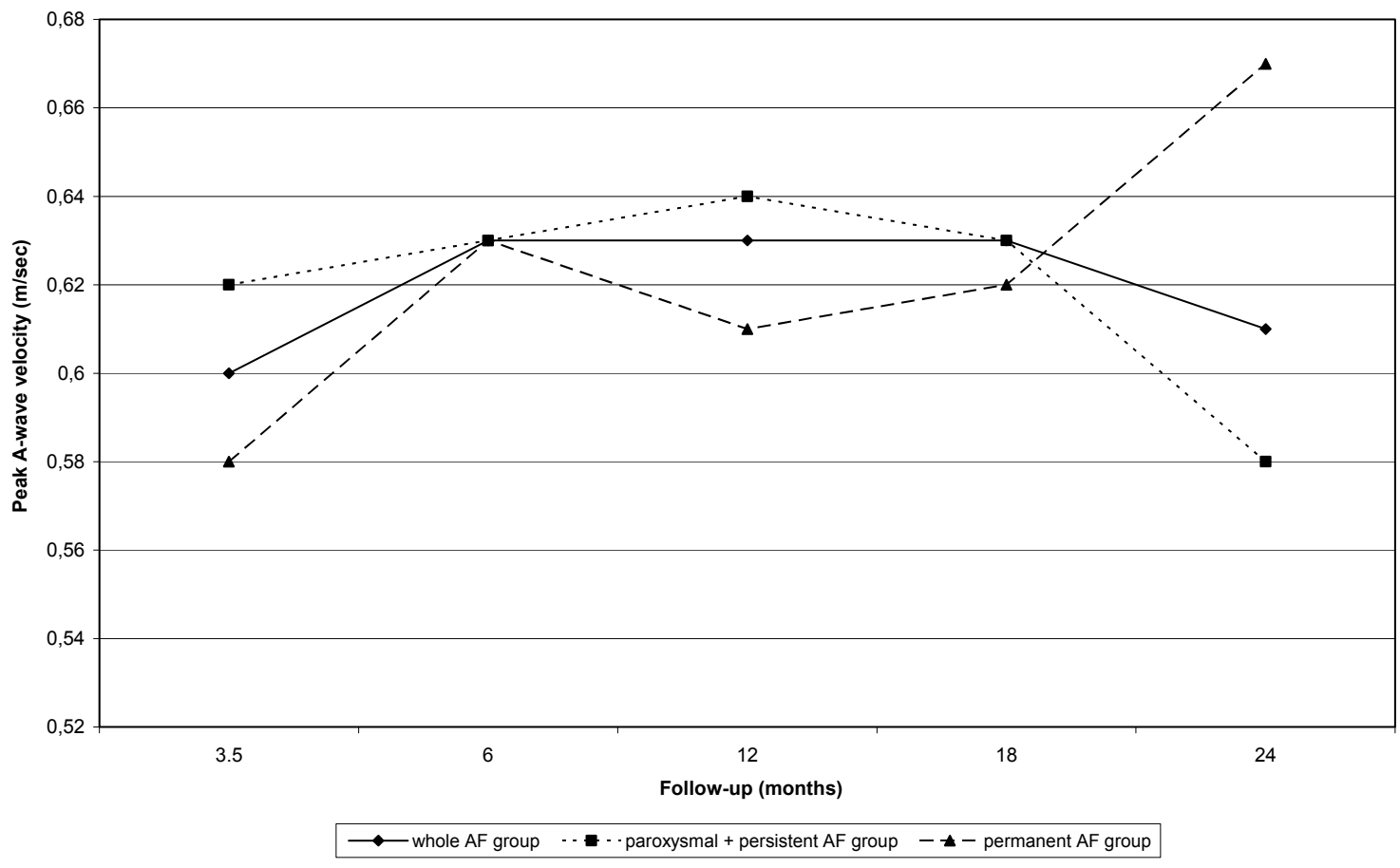

Fig. 4. Evaluation of postoperative peak transmitral A-wave velocity after the ablation procedure.

$\mathrm{AF}=$ atrial fibrillation

reason in the majority of cases was recurrence of $\mathrm{AF}$ (or other supraventricular tachyarrhythmia), with successful cardioversion to SR. The percentage of patients treated with AV-nodal-blocking agents also increased.

Electric cardioversion was more frequently indicated in the permanent AF group and in the course of the first six post-operative months (Table 5). A significant decrease in the frequency of DC cardioversions was always apparent between $6^{\text {th }}$ and $24^{\text {th }}$ month. The primary success rate of DC cardioversions of recurrent AF was high $(95 \%)$, without any influence of the pre-operative type of AF.

A total of $7 \%$ of patients had a permanent pacemaker implanted prior to the surgery (4 dual-chamber pace- 


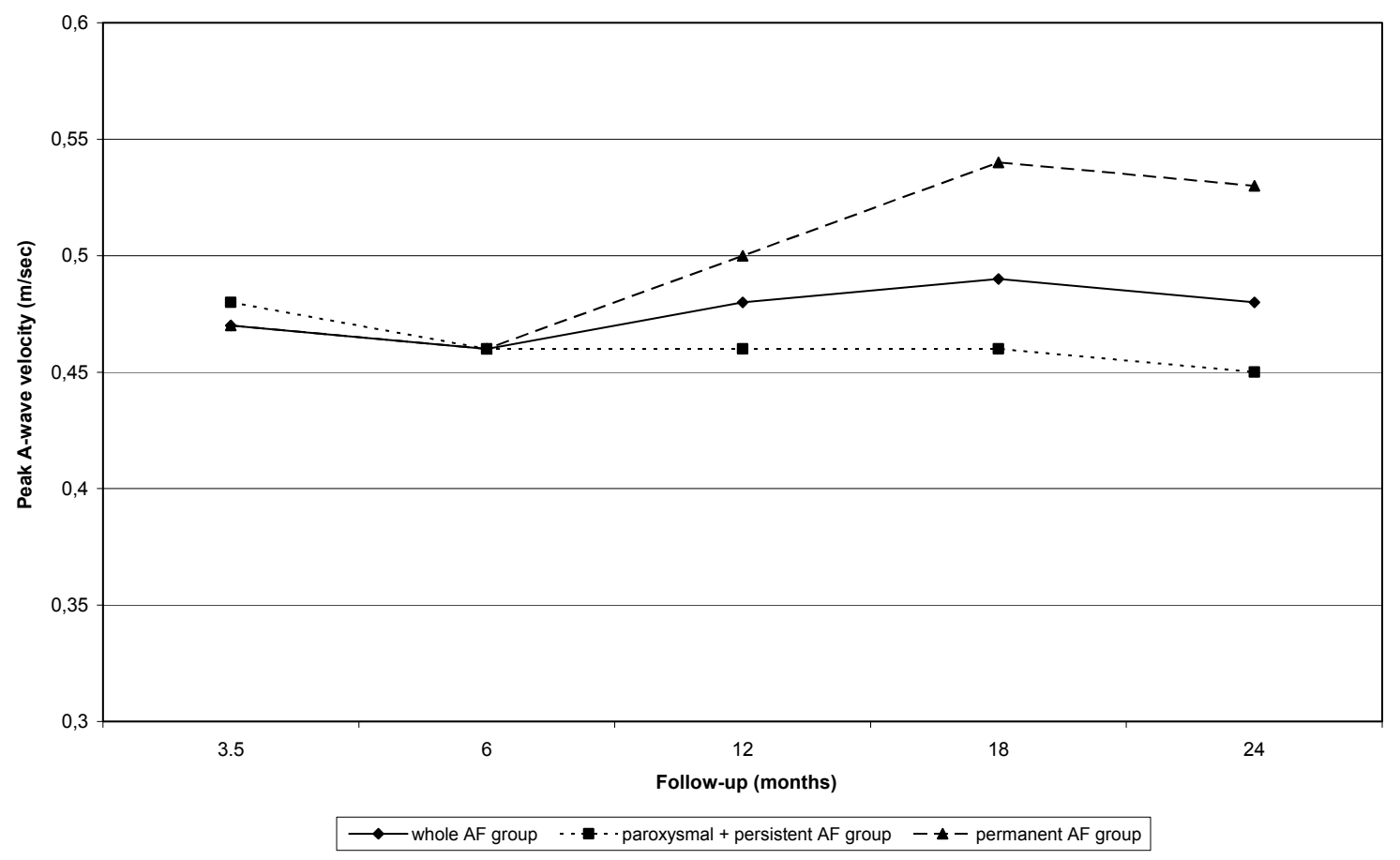

Fig. 5. Evaluation of postoperative peak transtricuspid A-wave velocity after the ablation procedure. $\mathrm{AF}=$ atrial fibrillation

makers, 3 single-chamber - VVI/R). The percentage of newly implanted pacemakers during the follow-up was relatively low, oscillating between $5 \%$ (discharge) and $10.3 \%$ (end of follow-up). The proportion of permanent pacemakers ranged overall from $12 \%$ (discharge) to $18 \%$ (24 months). All newly implanted pacemakers were dualchamber. The reason for a pacemaker implantation was sick sinus syndrome in 5 cases and second- and thirddegree atrio-ventricular block in three cases. One patient had an implantable cardioverter-defibrillator (ICD) implanted prior to the surgery. A further three patients had an ICD implantation in the post-operative period (two of them were cardiac resynchronization therapy devices and defibrillators).

\section{Predictors of the stable sinus rhythm}

The following factors were identified as significant negative predictors of the presence of SR following surgical ablation of AF: a growing left atrial size, duration of the atrial fibrillation and the mitral and tricuspid regurgitation severity before the surgery $(p<0.05)$.

\section{Atrial transport function \\ Left atrial transport function}

Effective mechanical function of the left atrium, following surgical ablation of AF, was detected in 70-90\% of patients with SR during the outpatient follow-ups (3.5, 6, 12, 18 and 24 months from the operation) (Table 6). It was more common in the group with paroxysmal + persistent (76-94\%), compared with permanent AF (57-82\%). However the difference was not statistically significant. The prevalence of left atrial transport function was generally increased during the follow-up period.
The mean value of the A-wave velocity of the transmitral flow (reflecting the intensity of left atrial contractions) increased slightly, but not significantly, during the follow-up in patients with preoperative permanent $\mathrm{AF}$ (Fig. 4). There was no difference between the curves which correspond to the mean velocity values of the A-wave in the groups of patients with paroxysmal + persistent and permanent AF.

\section{Right atrial transport function}

Effective transport function of the right atrium was found during individual outpatient follow-up examinations in $96-98 \%$ of cases (Table 7). No significant difference was found for right atrial transport function between the groups with paroxysmal + persistent AF (97-100\%) vs permanent AF (89-100\%). There was no significant difference in intensity of right atrial contractions between the groups (Fig. 5).

\section{Dynamics of selected echocardiographic parameters}

Compared to prior surgery, a statistically non-significant reduction in mean left atrial size $(1.3 \mathrm{~mm})$ was detected after 3.5 months in the whole group of patients. During subsequent follow-up, the left atrial diameter kept gradually rising, and almost reached preoperative value. The mean left ventricular end-diastolic diameter decreased non-significantly. The gradual decrease in endsystolic diameter of the left ventricle became significant after 18 months of follow-up ( $p<0.01$ ). The left ventricular ejection fraction kept slightly (but non-significantly) rising (Fig. 6).

Including the patients with SR in the course of the follow-up, the mean left atrial diameter decreased after 
Cardiac rhythm and atrial transport function after surgical ablation of atrial fibrillation using cryoenergy:

Table 6. Left atrial transport function.

\begin{tabular}{|c|c|c|c|c|c|c|c|c|}
\hline \multirow[t]{2}{*}{ Follow-up } & \multirow[t]{2}{*}{ Left ATF } & \multicolumn{2}{|c|}{ Whole AF group } & \multicolumn{2}{|c|}{$\begin{array}{c}\text { Paroxysmal + persistent } \\
\text { AF group }\end{array}$} & \multicolumn{2}{|c|}{ Permanent AF group } & \multirow[t]{2}{*}{$\mathrm{p}$ value } \\
\hline & & No. & $\%$ & No. & $\%$ & No. & $\%$ & \\
\hline \multirow{2}{*}{3.5 months } & present & 47 & 70.2 & 31 & 79.5 & 16 & 57.1 & \multirow{2}{*}{0.05} \\
\hline & $\mathrm{n}$ & 67 & 100.0 & 39 & 100.0 & 28 & 100.0 & \\
\hline \multirow{2}{*}{6 months } & present & 47 & 71.2 & 29 & 76.3 & 18 & 64.3 & \multirow{2}{*}{ NS } \\
\hline & $\mathrm{n}$ & 66 & 100.0 & 38 & 100.0 & 28 & 100.0 & \\
\hline \multirow{2}{*}{12 months } & present & 52 & 85.3 & 32 & 91.4 & 20 & 76.9 & \multirow{2}{*}{ NS } \\
\hline & $\mathrm{n}$ & 61 & 100.0 & 35 & 100.0 & 26 & 100.0 & \\
\hline \multirow[t]{2}{*}{18 months } & present & 52 & 81.3 & 32 & 84.2 & 20 & 76.9 & \multirow{2}{*}{ NS } \\
\hline & $\mathrm{n}$ & 64 & 100.0 & 38 & 100.0 & 26 & 100.0 & \\
\hline \multirow[t]{2}{*}{24 months } & present & 51 & 89.5 & 33 & 94.3 & 18 & 81.8 & \multirow{2}{*}{ NS } \\
\hline & $\mathrm{n}$ & 57 & 100.0 & 35 & 100.0 & 22 & 100.0 & \\
\hline
\end{tabular}

$\mathrm{AF}=$ atrial fibrillation, $\mathrm{ATF}=$ atrial transport function

NS - non significant

Table 7. Right atrial transport function.

\begin{tabular}{|c|c|c|c|c|c|c|c|c|}
\hline \multirow[t]{2}{*}{ Follow-up } & \multirow[t]{2}{*}{ Right ATF } & \multicolumn{2}{|c|}{ Whole AF group } & \multicolumn{2}{|c|}{$\begin{array}{c}\text { Paroxysmal + persistent } \\
\text { AF group }\end{array}$} & \multicolumn{2}{|c|}{ Permanent AF group } & \multirow[t]{2}{*}{$\mathrm{p}$ value } \\
\hline & & No. & $\%$ & No. & $\%$ & No. & $\%$ & \\
\hline \multirow[t]{2}{*}{3.5 months } & present & 64 & 97.0 & 38 & 97.4 & 26 & 96.3 & \multirow{2}{*}{ NS } \\
\hline & $\mathrm{n}$ & 66 & 100.0 & 39 & 100.0 & 27 & 100.0 & \\
\hline \multirow[t]{2}{*}{6 months } & present & 63 & 95.5 & 38 & 100.0 & 25 & 89.3 & \multirow{2}{*}{ NS } \\
\hline & $\mathrm{n}$ & 66 & 100.0 & 38 & 100.0 & 28 & 100.0 & \\
\hline \multirow[t]{2}{*}{12 months } & present & 59 & 98.3 & 33 & 97.1 & 26 & 100.0 & \multirow{2}{*}{ NS } \\
\hline & $\mathrm{n}$ & 60 & 100.0 & 34 & 100.0 & 26 & 100.0 & \\
\hline \multirow[t]{2}{*}{18 months } & present & 61 & 98.4 & 37 & 100.0 & 24 & 96.0 & \multirow{2}{*}{ NS } \\
\hline & $\mathrm{n}$ & 62 & 100.0 & 37 & 100.0 & 25 & 100.0 & \\
\hline \multirow[t]{2}{*}{24 months } & present & 54 & 98.2 & 33 & 100.0 & 21 & 95.5 & \multirow{2}{*}{ NS } \\
\hline & $\mathrm{n}$ & 55 & 100.0 & 33 & 100.0 & 22 & 100.0 & \\
\hline
\end{tabular}

$\mathrm{AF}=$ atrial fibrillation, $\mathrm{ATF}=$ atrial transport function NS - non significant

3.5 months by $1.9 \mathrm{~mm}$, further on, the left atrium increased in size progressively but did not reach its original dimension. We found a gradual increase in the left atrial size in patients with persistent AF or another supraventricular tachyarrhythmia, which reached $1.3 \mathrm{~mm}$ after 2 years. Both were statistically non-significant.

The mean severity of the mitral and tricuspid regurgitation was significantly reduced after the operation ( $p<0.001$ and $p<0.02$ ), because $74 \%$ of patients underwent mitral valve surgery (repair or replacement) and 33\% of all patients a tricuspid valve annuloplasty (Fig. 7). The most significant decrease in mitral and tricuspid regurgitant severity was found one week after the operation $(p<0.001)$ in the course of a check up echocardiography prior to discharge. The mitral regurgitation severity remained significantly decreased for the whole follow-up period and there was no significant worsening of the condition between 3.5 and 24 months postoperatively. The reduction 


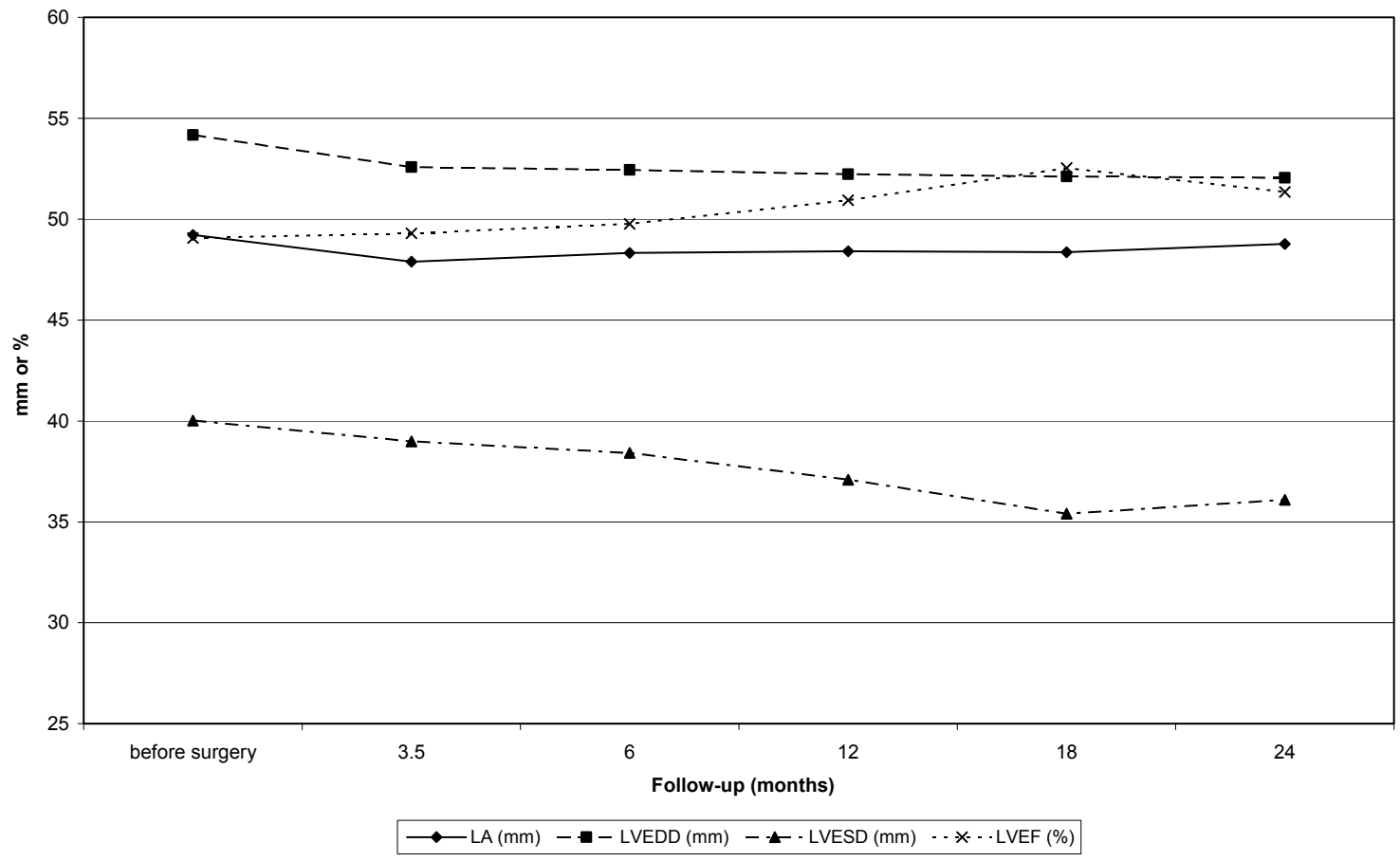

Fig. 6. Evaluation of atrial and ventricular measurements by echocardiography before and after the operation $\mathrm{LA}=$ left atrium, $\mathrm{LVEDD}=$ left ventricular end diastolic diameter, $\mathrm{LVEF}=$ left ventricular ejection fraction, LVESD = left ventricular end systolic diameter.

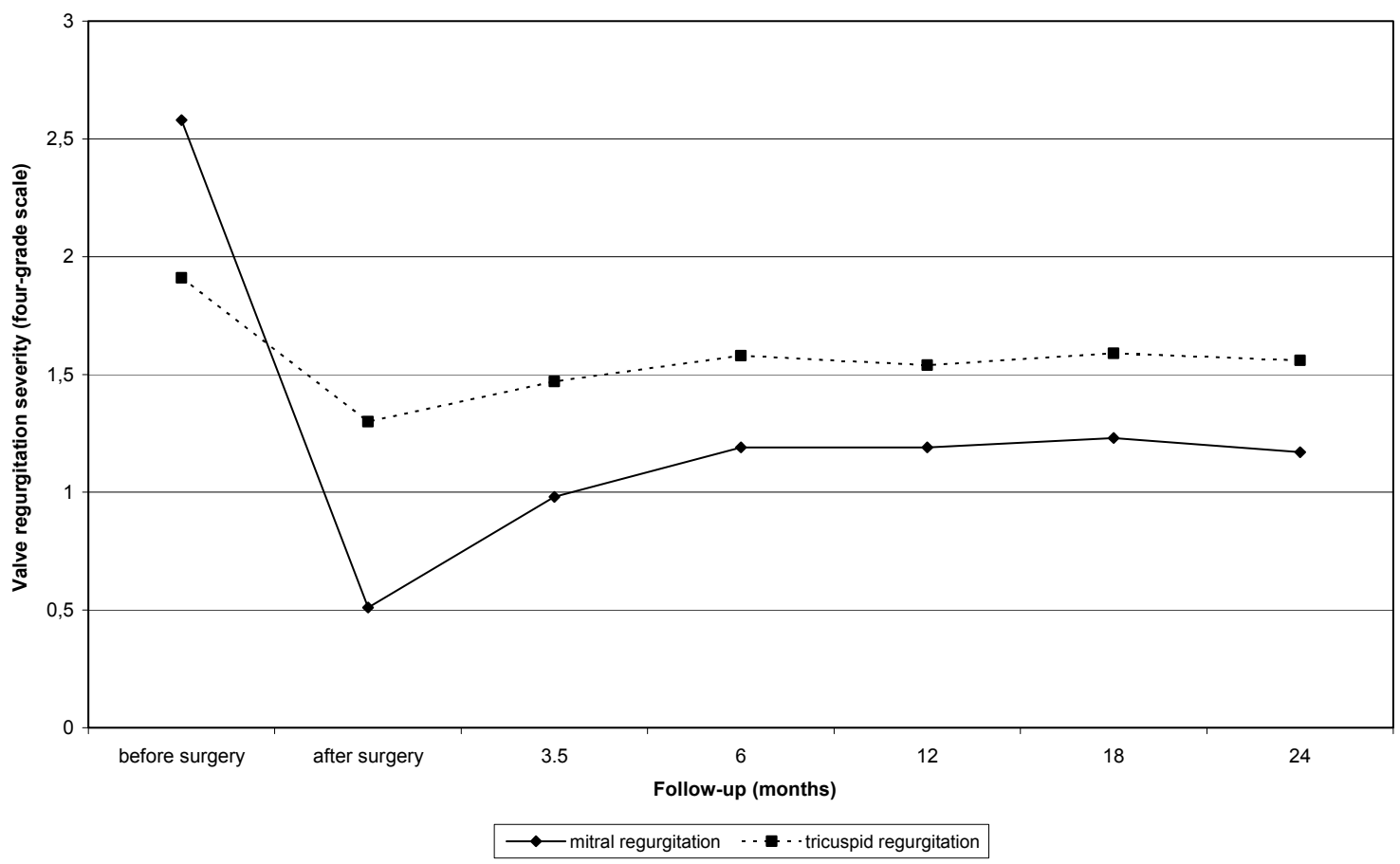

Fig. 7. Echocardiographic evaluation of mitral and tricuspid-valve regurgitation severity (four-grade scale) before and after the operation.

of tricuspid regurgitation severity was still significant after 3.5 months. Later on the values were the same as the pre-operative state.
Predictors for restoration of left atrial transport function

Recovery or maintenance of the left atrial transport function was predicted negatively from the pre-operative left atrial size, the presence of mitral stenosis and the significance of tricuspid regurgitation $(\mathrm{p}<0.05)$. 


\section{Complications, mortality}

\section{Embolic complications}

We encountered altogether 7 non-fatal ischemic strokes - two of these were related to the surgery and five were late ones. The parameter "freedom from stroke" (evaluating late strokes) reached $95.4 \%$ at a one-year follow-up and $94.1 \%$ at two years from the surgery. One patient died during the hospitalization period as a consequence of vascular ileus due to acute obstruction of the superior mesenteric artery.

\section{In-hospital surgical complications}

Early post-operative surgical complications were as follows: 7 revisions for postoperative bleeding, 2 revisions due to haemopericardium with cardiac tamponade, 5 cases of pericardiocentesis for clinically significant pericardial effusion, 1 significant pericardial effusion with regression after conservative therapy, 1 acute thrombotic obstruction of the right femoral artery following an attempt to insert intra-aortic balloon counterpulsation and 1 early reoperation - mitral valve replacement with mechanical prosthesis in a patient after a mitral valve plasty with a severe residual regurgitation.

\section{Thirty-day and overall mortality rate}

Thirty-day mortality reached $12 \%$ (12 deaths). The cause of death was cardiac-related in 5 patients (cardiogenic shock or progression of heart failure in 4 cases, sudden arrhythmic death in one case), 5 patients died as a consequence of multiple organ failure, one patient due to bilateral bronchopneumonia and one patient due to the already mentioned vascular ileus. The predicted operative mortality according to EuroSCORE was $8 \%$.

Ten other patients died in the course of the subsequent follow-up, the overall mortality rate thus reaching $22 \%$. The causes of death - heart failure in 3 cases, pulmonary embolism in one case, hemorrhagic stroke in one case, brain tumour in one case, pneumonia following Ender osteosynthesis for neck fracture of the femur in one case, sepsis due to large lower limb defects in a patient with Lerich syndrome, sepsis due to large ulcus cruris in a patient with a generalized kidney cancer, and finally sepsis due to progressive osteomyelitis of the sternum.

\section{DISCUSSION}

Surgical ablation is considered to be one of the most effective currently used methods for the treatment of atrial fibrillation, mainly its chronic form. According to the literature, the sinus rhythm in patients with paroxysmal AF can be observed after ablation in more than 90-95\% of cases during out-patient clinical examinations ${ }^{17}$. Sinus rhythm is usually restored in $60-80 \%$ of patients with originally permanent $\mathrm{AF}^{18-22}$. Mixed groups show the success rate of surgical ablation reaching approximately $80 \%$ $\left(\right.$ ref. $\left.^{23-25}\right)$. Our results were similar.

Taking into consideration the fact that early postoperative AF recurrences may be caused by different pathophysiological mechanisms (e.g. the impact of heart surgery), the late recurrence of arrhythmias is usually assessed after the first three months from surgery (the "freedom from recurrent atrial fibrillation" parameter, including recurrent AF during the scheduled medical check-ups, or "freedom from permanent atrial fibrillation", relevant only to patients with permanent AF following surgical ablation). The results differ according to the methodology used and exactness of the dispensing applied. During a 1-5 year follow-up in the studies mentioned below, there were $74-89 \%$ of patients "free from recurrent AF" and $79-98 \%$ of patients "free from permanent AF"18,26-30. To be able to assess the "freedom from AF" parameter in a similar analysis, we used more strict criteria than is usual in the published literature. For this reason, comparison is not possible. "Vague analysis" of the heart rhythm taking into account the present state only during the scheduled out-patient medical check-ups, leads to better results comparable with the published literature.

A routine use of Holter ECG monitoring after the ablation of AF increases the percentage of patients with asymptomatic AF recurrences. Recent publications concentrate on the precision of detecting symptomatic, as well as asymptomatic, attacks of arrhythmia in patients following radiofrequency catheter ablation for paroxysmal and persistent $\mathrm{AF}^{31-35}$ (there are practically no data concerning the occurrence of AF episodes using long-term ECG monitoring after surgical ablation of paroxysmal, persistent and permanent AF available). The techniques used include a trans-telephone ECG monitoring, sevenday Holter monitoring and continuous ECG monitoring either with sophisticated pacemakers and cardioverters - defibrillators (application of their Holter functions), or with implantable loop recorders (Reveal, Medtronic Inc., Minneapolis, Minnesota). The ablation leads to a significant reduction in arrhythmia burden, but also to an increase in asymptomatic AF paroxysms. The clinical importance of the detected asymptomatic AF episodes has not yet been clarified sufficiently, and subject to ongoing clinical trials. It is not clear whether anticoagulation treatment should be given to patients with short paroxysms of AF. However, the increased risk of thromboembolic complications in relation to the duration of AF attacks has been found. Episodes of AF exceeding a period of 24 hours were, in one study ${ }^{36}$, associated with triple risk of arterial embolisation. The indication for anticoagulation seems to be subject of individual decision. We should decide upon the presence of risk factors of thromboembolism $\left(\mathrm{CHADS}_{2} \text { risk criteria and scoring etc. }\right)^{37}$. A similarly individualised approach is applied to the indication for and administration of an antiarrhythmic therapy.

Recurrences of AF or any other supraventricular tachyarrhythmia were the reason for DC cardioversion (on individual basis - as mentioned earlier). The significant decrease in cardioversion rate between $6^{\text {th }}$ and $24^{\text {th }}$ month after surgery was most probably caused by overcoming the initial period of arrhythmic instability, conditioned by the impact of heart surgery and the process of cryolesion healing. In several patients, no further cardioversion was performed due to frequent AF recurrence. 
Permanent pacemaker requirement used to be higher after maze I and II procedures (up to $40 \%$ of patients) ${ }^{38}$. With the implementation of the maze III procedure and with the use of alternative sources of energy, the frequency of pacemaker placement has decreased to $5-13 \%$ according to several studies ${ }^{18,22,27,30,39}$. Other authors assessed the need for permanent cardiostimulation after surgery as, as much as $20 \%$ (ref. $^{20,26,40}$ ). In our case, the percentage of newly implanted pacemakers in the post-operative period was relatively low, from around 5\% at the time of discharge up to $10.3 \%$ at the end of follow-up. The indications for pacemaker implantation were common one.

The increasing size of the left atrium and the duration of AF before the operation are considered to be negative predictors of achieving and maintaining SR after surgery ${ }^{19,20,30,41-46}$. In our patients too, a large preoperative left atrial diameter was a negative predicting factor. We did not test the relation between the AF duration before the surgery and the result of left atrial cryoablation. However, patients with paroxysmal or persistent AF maintained SR significantly more often during the follow-up period than patients with permanent AF. The severity of the tricuspid regurgitation was a marker of degree of pathophysiological and morphological changes in the left atrium in cases of long-lasting AF and with the basic heart disease (usually mitral valve lesion, complicated with tricuspidalisation), and was associated with a higher probability of AF recurrence.

The presence of a stable SR is related to restoration or preservation of atrial mechanical function. The literature shows that an effective left atrial transport function is diagnosed in 60-90\% and effective right atrial contractions are detected in $80-100 \%$ of patients with $\mathrm{SR}^{18,20,38,47-52}$. Our results correspond with these findings - mechanical function of the left atrium in $70-90 \%$ and of the right atrium in $96-98 \%$ of patients with SR. The left atrial transport function was less commonly observed than the function of right atrium; this is caused by the predominance of morphologic and pathophysiologic changes in the left atrium in relation to the presence of AF and reasons for the basic heart disease. The non-significantly lower prevalence of left atrial mechanical function in the permanent AF subgroup may be explained by the degree of atrial remodellation. The prevalence of the effective left atrial transport function increased overall with length of follow-up period.

Some studies have reported an improvement in the intensity of left atrial contractions over time ${ }^{53,54}$. Different results were published by $\mathrm{Yuda}^{55}$ - the intensity of contractions of the left atrium did not alter significantly over time. We found no significant increase in intensity of left or right atrial contractions either.

The changes in left atrial diameter following the maze procedure have been assessed for example by Yuda or Lönnerholm ${ }^{55,56}$, who report a significant decrease in size of the left atrium early after the procedure, without any further development in the course of the follow-up. However, in another study ${ }^{57}$, it was not the maze procedure that contributed to the reduction of left atrial volume but mitral valve surgery. We observed an initial decrease in the mean left atrial diameter in our group (globally, as well as in patients with stable SR), but it was not significant. Apart from reverse remodelling following the elimination of a severe mitral valve lesion and the elimination of AF, it is also the performance of sutures and scarring after the maze procedure (present most often after a classical "cut and sew" procedure) that contributes to left atrial volume reduction. We did not perform a surgical reduction of the left atrium size (as a part of the procedure).

The dynamics of proportions and the ejection fraction of the left ventricle is more determined by the surgical correction of valvular disease or revascularisation than by the absence of AF.

The following conditions are commonly considered to be predictors of a restoration of the left atrial transport function: the left atrial size and the duration of AF before surgery (identical factors as in the case of heart rhythm $)^{47,52,58,59}$. In our study we identified these negative predictors of the presence of mechanical left atrial function: the increasing left atrial diameter, the presence of mitral stenosis and growing tricuspid regurgitation severity before the operation. The explanation is most probably again in a more advanced remodellation of the left atrium in patients with mitral stenosis and mitral valve lesion complicated with tricuspidalisation.

Left untreated, AF increases morbidity and mortality in patients undergoing mitral valve surgery ${ }^{60}$. Separate surgical correction of mitral valve disease does not lead to restoration of SR in the majority of patients ${ }^{22,27,28,61-63}$. Similarly, AF diagnosed before CABG surgery is associated with a decrease in the mean long-term survival rate after the operation ${ }^{64}$ which is why simultaneous surgical ablation for AF is recommended.

Another important benefit of the AF ablation is the reduction of embolisation-related complications, namely late ischemic strokes. In the study described by Bando ${ }^{27}$ there were $97 \%$ of patients "free from stroke" at 5-year follow-up after a combined surgical intervention - maze procedure + mitral valve surgery, however only $79 \%$ of patients following an isolated mitral valve replacement. Similarly, the meta-analysis carried out by Reston ${ }^{63}$ found a significant reduction in stroke rates ( 0 vs $5.8 \%$ ) following the maze procedure. In our group, the incidence of late ischemic strokes was higher than described in the literature; a total of $95.4 \%$ of patients were "free from stroke" at one-year follow-up, and $94.1 \%$ at 2-year followup. The reason in two patients was a sub-therapeutic INR level. The two perioperative strokes may have been caused by embolisation of thrombotic or atheromal masses during the manipulation with ascending aorta in the course of heart operation.

The 30-day mortality in the group was high (12\%). The literature quotes the 30-day mortality as single digit per cent only. Also the overall mortality was rather high (22\%). This corresponds with the high level of risk factors associated with the patients in our study. 


\section{CONCLUSION}

Surgical ablation for atrial fibrillation using cryoenergy is an effective treatment, enabling us to achieve and maintain sinus rhythm in a high proportion of patients and also an early restoration of effective mechanical atrial function. Stable sinus rhythm and an effective left atrial transport function are the main factors resulting in a decrease in morbidity after a successful ablation of atrial fibrillation.

Careful post-operative follow-up of the patients and individualised management of the treatment are necessary. From the point of view of evaluating ablation procedures, these are very useful methods, enabling more precise and longer-term monitoring of the heart rhythm in the postoperative period. We hope that the ongoing clinical trials will yield the necessary data for more accurate indications or modification of the anticoagulative and antiarrhythmic therapy in relation to atrial arrhythmia burden. The presence of effective left atrial mechanical function is an additional criterion in the process of discontinuation or further administration of anticoagulation.

\section{REFERENCES}

1. Go AS, Hylek EM, Phillips KA, Chang Y, Henault LE, Selby JV et al. Prevalence of diagnosed atrial fibrillation in adults: national implications for rhythm management and stroke prevention: the AnTicoagulation and Risk Factors in Atrial Fibrillation (ATRIA) Study. JAMA 2001; 285:2370-2375.

2. Feinberg WM, Blackshear JL, Laupacis A, Kronmal R, Hart RG. Prevalence, age distribution, and gender of patients with atrial fibrillation. Analysis and implications. Arch Intern Med 1995; 155:469-473.

3. Kannel WB, Wolf PA, Benjamin EJ, Levy D. Prevalence, incidence, prognosis, and predisposing conditions for atrial fibrillation: population-based estimates. Am J Cardiol 1998; 82:2N-9N.

4. Ryder KM, Benjamin EJ. Epidemiology and significance of atrial fibrillation. Am J Cardiol 1999; 84:131R-138R.

5. Kannel WB, Abbott RD, Savage DD, McNamara PM. Epidemiologic features of chronic atrial fibrillation: the Framingham study. N Engl J Med 1982; 306:1018-1022.

6. Cleland JGF, Swedberg K, Follath F, Komajda M, Cohen-Solal A, Aguilar JC et al. The EuroHeart Failure survey programme - a survey on the quality of care among patients with heart failure in Europe. Part 1: patient characteristics and diagnosis. Eur Heart J 2003; 24:442-463.

7. Camm AJ, Savelieva I. Atrial fibrillation: advances and perspectives. Dialog Cardiovasc Med 2003; 8:183-202.

8. Cohn LH, Couper GS, Aranki SF, Rizzo RJ, Kinchla NM, Collins JJ. Long-term results of mitral valve reconstruction for regurgitation of the myxomatous mitral valve. J Thorac Cardiovasc Surg 1994; 107:143-50; discussion 150.

9. David TE, Armstrong S, Sun Z, Daniel L. Late results of mitral valve repair for mitral regurgitation due to degenerative disease. Ann Thorac Surg 1993; 56:7-12; discussion 13.

10. Alvarez JM, Deal CW, Loveridge K, Brennan P, Eisenberg R, Ward $\mathrm{M}$ et al. Repairing the degenerative mitral valve: ten- to fifteen-year follow-up. J Thorac Cardiovasc Surg 1996; 112:238-247.

11. Cox JL. Intraoperative options for treating atrial fibrillation associated with mitral valve disease. J Thorac Cardiovasc Surg 2001; 122:212-215.

12. Dries DL, Exner DV, Gersh BJ, Domanski MJ, Waclawiw MA, Stevenson LW. Atrial fibrillation is associated with an increased risk for mortality and heart failure progression in patients with asymptomatic and symptomatic left ventricular systolic dysfunction: a retrospective analysis of the SOLVD trials. Studies of Left Ventricular Dysfunction. J Am Coll Cardiol 1998; 32:695-703.

13. Hamer ME, Blumenthal JA, McCarthy EA, Phillips BG, Pritchett EL. Quality-of-life assessment in patients with paroxysmal atrial fibrillation or paroxysmal supraventricular tachycardia. Am J Cardiol 1994; 74:826-829.

14. Atrial Fibrillation Investigators. Risk factors for stroke and efficacy of antithrombotic therapy in atrial fibrillation Analysis of pooled data from five randomized controlled trials. Arch Intern Med 1994;154:1449-57. Erratum in: Arch Intern Med 1994;154:2254.

15. Benjamin EJ, Wolf PA, D'Agostino RB, Silbershatz H, Kannel WB, Levy D. Impact of atrial fibrillation on the risk of death: the Framingham Heart Study. Circulation 1998; 98:946-952.

16. Cox JL, Jaquiss RD, Schuessler RB, Boineau JP. Modification of the maze procedure for atrial flutter and atrial fibrillation. II. Surgical technique of the maze III procedure. J Thorac Cardiovasc Surg 1995; 110:485-495

17. Jessurun ER, van Hemel NM, Defauw JA, Stofmeel MA, Kelder $\mathrm{JC}$, de la Rivière $\mathrm{AB}$ et al. Results of maze surgery for lone paroxysmal atrial fibrillation. Circulation 2000; 101:1559-1567.

18. Sie HT, Beukema WP, Misier AR, Elvan A, Ennema JJ, Haalebos $\mathrm{MM}$ et al. Radiofrequency modified maze in patients with atrial fibrillation undergoing concomitant cardiac surgery. J Thorac Cardiovasc Surg 2001; 122:249-256.

19. Tada H, Ito S, Naito S, Hasegawa Y, Kurosaki K, Ezure M et al Long-term results of cryoablation with a new cryoprobe to eliminate chronic atrial fibrillation associated with mitral valve disease. Pacing Clin Electrophysiol 2005; 28 Suppl 1:S73-S77.

20. Imai K, Sueda T, Orihashi K, Watari M, Matsuura Y. Clinical analysis of results of a simple left atrial procedure for chronic atrial fibrillation. Ann Thorac Surg 2001; 71:577-581.

21. Benussi S, Pappone C, Nascimbene S, Oreto G, Caldarola A, Stefano PL et al. A simple way to treat chronic atrial fibrillation during mitral valve surgery: the epicardial radiofrequency approach. Eur J Cardiothorac Surg 2000; 17:524-529.

22. Raanani E, Albage A, David TE, Yau TM, Armstrong S. The efficacy of the Cox/maze procedure combined with mitral valve surgery: a matched control study. Eur J Cardiothorac Surg 2001; 19:438-442.

23. Mantovan R, Raviele A, Buja G, Bertaglia E, Cesari F, Pedrocco A et al. Left atrial radiofrequency ablation during cardiac surgery in patients with atrial fibrillation. J Cardiovasc Electrophysiol 2003; 14:1289-1295.

24. Starck C, Botha CA, Roser D, Paula J, Rein JG, Hemmer W. Results of a modified left atrial maze procedure as a combined procedure. Thorac Cardiovasc Surg 2003; 51:147-153.

25. Doll N, Kiaii BB, Fabricius AM, Bucerius J, Kornherr P, Krakor R et al. Intraoperative left atrial ablation (for atrial fibrillation) using a new argon cryocatheter: early clinical experience. Ann Thorac Surg 2003; 76:1711-5; discussion 1715.

26. Mack CA, Milla F, Ko W, Girardi LN, Lee LY, Tortolani AJ et al. Surgical treatment of atrial fibrillation using argon-based cryoablation during concomitant cardiac procedures. Circulation 2005; 112:I1-I6.

27. Bando K, Kobayashi J, Kosakai Y, Hirata M, Sasako Y, Nakatani S et al. Impact of Cox maze procedure on outcome in patients with atrial fibrillation and mitral valve disease. J Thorac Cardiovasc Surg 2002; 124:575-583

28. Handa N, Schaff HV, Morris JJ, Anderson BJ, Kopecky SL, Enriquez-Sarano M. Outcome of valve repair and the Cox maze procedure for mitral regurgitation and associated atrial fibrillation. J Thorac Cardiovasc Surg 1999; 118:628-635.

29. Nakajima H, Kobayashi J, Bando K, Niwaya K, Tagusari O, Sasako $\mathrm{Y}$ et al. The effect of cryo-maze procedure on early and intermediate term outcome in mitral valve disease: case matched study. Circulation 2002; 106:I46-I50.

30. Halkos ME, Craver JM, Thourani VH, Kerendi F, Puskas JD, Cooper WA et al. Intraoperative radiofrequency ablation for the treatment of atrial fibrillation during concomitant cardiac surgery. Ann Thorac Surg 2005; 80:210-5; discussion 215. 
31. Kottkamp H, Tanner H, Kobza R, Schirdewahn P, Dorszewski A, Gerds-Li JH et al. Time courses and quantitative analysis of atrial fibrillation episode number and duration after circular plus linear left atrial lesions: trigger elimination or substrate modification: early or delayed cure? J Am Coll Cardiol 2004; 44:869-877.

32. Montenero AS, Quayyum A, Franciosa P, Mangiameli D, Antonelli A, Barbieri L et al. Implantable loop recorders: a novel method to judge patient perception of atrial fibrillation. Preliminary results from a pilot study. J Interv Card Electrophysiol 2004; 10:211-220.

33. Senatore G, Stabile G, Bertaglia E, Donnici G, De Simone A, Zoppo F et al. Role of transtelephonic electrocardiographic monitoring in detecting short-term arrhythmia recurrences after radiofrequency ablation in patients with atrial fibrillation. J Am Coll Cardiol 2005; 45:873-876.

34. Martinek M, Aichinger J, Nesser HJ, Ziegler PD, Purerfellner H New insights into long-term follow-up of atrial fibrillation ablation: full disclosure by an implantable pacemaker device. J Cardiovasc Electrophysiol 2007; 18:818-823.

35. Steven D, Rostock T, Lutomsky B, Klemm H, Servatius H, Drewitz I et al. What is the real atrial fibrillation burden after catheter ablation of atrial fibrillation? A prospective rhythm analysis in pacemaker patients with continuous atrial monitoring. Eur Heart J 2008; 29:1037-1042.

36. Capucci A, Santini M, Padeletti L, Gulizia M, Botto G, Boriani G et al. Monitored atrial fibrillation duration predicts arterial embolic events in patients suffering from bradycardia and atrial fibrillation implanted with antitachycardia pacemakers. J Am Coll Cardiol 2005; 46:1913-1920.

37. Fuster V, Rydén LE, Cannom DS, Crijns HJ, Curtis AB, Ellenbogen KA. ACC/AHA/ESC 2006 guidelines for the management of patients with atrial fibrillation: full text: a report of the American College of Cardiology/American Heart Association Task Force on practice guidelines and the European Society of Cardiology Committee for Practice Guidelines (Writing Committee to Revise the 2001 guidelines for the management of patients with atria fibrillation) developed in collaboration with the European Heart Rhythm Association and the Heart Rhythm Society. Europace 2006;8:651-745. Erratum in: Europace 2007;9:856.

38. Cox JL, Boineau JP, Schuessler RB, Kater KM, Lappas DG. Fiveyear experience with the maze procedure for atrial fibrillation. Ann Thorac Surg 1993; 56:814-823; discussion 823.

39. Izumoto H, Kawazoe K, Eishi K, Kamata J. Medium-term results after the modified Cox/Maze procedure combined with other cardiac surgery. Eur J Cardiothorac Surg 2000; 17:25-29.

40. Ryan WH, Prince HB, Wheatley GH, Herbert MA, Worley CM, Prince SL et al. Experience with various surgical options for the treatment of atrial fibrillation. Heart Surg Forum 2004; 7:E333-6; discussion E336.

41. Chen MC, Chang JP, Chang HW. Preoperative atrial size predicts the success of radiofrequency maze procedure for permanent atrial fibrillation in patients undergoing concomitant valvular surgery. Chest 2004; 125:2129-2134.

42. Chen MC, Chang JP, Chang HW, Chen CJ, Yang CH, Chen YH et al. Clinical determinants of sinus conversion by radiofrequency maze procedure for persistent atrial fibrillation in patients undergoing concomitant mitral valvular surgery. Am J Cardiol 2005; 96:1553-1557

43. Gaynor SL, Schuessler RB, Bailey MS, Ishii Y, Boineau JP, Gleva $\mathrm{MJ}$ et al. Surgical treatment of atrial fibrillation: predictors of late recurrence. J Thorac Cardiovasc Surg 2005; 129:104-111.

44. Isobe N, Taniguchi K, Oshima S, Kamiyama H, Ezure M, Kaneko $\mathrm{T}$ et al. Factors predicting success in cryoablation of the pulmonary veins in patients with chronic atrial fibrillation. Circ J 2004; 68:999-1003.

45. Gillinov AM, Bhavani S, Blackstone EH, Rajeswaran J, Svensson LG, Navia JL et al. Surgery for permanent atrial fibrillation: impact of patient factors and lesion set. Ann Thorac Surg 2006; 82:50213; discussion 513 .
46. Grubitzsch H, Beholz S, Dohmen PM, Dushe S, Liu J, Konertz W. Ablation of atrial fibrillation in valvular heart surgery: are results determined by underlying valve disease? J Heart Valve Dis 2007; 16:76-83.

47. Bauer EP, Szalay ZA, Brandt RR, Pitschner HF, Bachmann G, Brunner-La Rocca HP et al. Predictors for atrial transport function after mini-maze operation. Ann Thorac Surg 2001; 72:1251-4; discussion 1255 .

48. Cox JL. Atrial transport function after the maze procedure for atrial fibrillation: a 10-year clinical experience. Am Heart J 1998; 136:934-936.

49. Ad N, Cox JL. The Maze procedure for the treatment of atrial fibrillation: a minimally invasive approach. J Card Surg 2004; 19:196-200.

50. Feinberg MS, Waggoner AD, Kater KM, Cox JL, Lindsay BD, Pérez JE. Restoration of atrial function after the maze procedure for patients with atrial fibrillation. Assessment by Doppler echocardiography. Circulation 1994; 90:II285-II292.

51. Albirini A, Scalia GM, Murray RD, Chung MK, McCarthy PM, Griffin BP et al. Left and right atrial transport function after the Maze procedure for atrial fibrillation: an echocardiographic Doppler follow-up study. J Am Soc Echocardiogr 1997; 10:937945.

52. Isobe F, Kawashima Y. The outcome and indications of the Cox maze III procedure for chronic atrial fibrillation with mitral valve disease. J Thorac Cardiovasc Surg 1998; 116:220-227.

53. Lee JW, Choo SJ, Kim KI, Song JK, Kang DH, Song JM et al. Atrial fibrillation surgery simplified with cryoablation to improve left atrial function. Ann Thorac Surg 2001; 72:1479-1483.

54. Sou T, Yukiko N, Tetsuji S, Kazuaki C, Katsuhiko I, Taijiro S. Atrial contraction after surgical isolation of the left atrial posterior wall concomitant with mitral valve replacement. Circ J 2004; 68:204-207.

55. Yuda S, Nakatani S, Kosakai Y, Yamagishi M, Miyatake K. Longterm follow-up of atrial contraction after the maze procedure in patients with mitral valve disease. J Am Coll Cardiol 2001; 37:1622-1627.

56. Lönnerholm S, Blomström P, Nilsson L, Blomström-Lundqvist C Atrial size and transport function after the Maze III procedure for paroxysmal atrial fibrillation. Ann Thorac Surg 2002; 73:107-111.

57. Jessurun ER, van Hemel NM, Kelder JC, Defauw JAMT, Brutel de la Rivière A, Ernst JMPG et al. The effect of maze operations on atrial volume. Ann Thorac Surg 2003; 75:51-56.

58. Kim YJ, Sohn DW, Park DG, Kim HS, Oh BH, Lee MM et al. Restoration of atrial mechanical function after maze operation in patients with structural heart disease. Am Heart J 1998; 136:10701074

59. Yashima N, Nasu M, Kawazoe K, Hiramori K. Serial evaluation of atrial function by Doppler echocardiography after the maze procedure for chronic atrial fibrillation. Eur Heart J 1997; 18:496-502.

60. Gillinov AM. Ablation of atrial fibrillation with mitral valve surgery. Curr Opin Cardiol 2005; 20:107-114

61. Sueda T, Nagata H, Orihashi K, Morita S, Okada K, Sueshiro M et al. Efficacy of a simple left atrial procedure for chronic atrial fibrillation in mitral valve operations. Ann Thorac Surg 1997; 63:1070-1075.

62. Jessurun ER, van Hemel NM, Kelder JC, Elbers S, de la Rivière $\mathrm{AB}$, Defauw JJ et al. Mitral valve surgery and atrial fibrillation: is atrial fibrillation surgery also needed? Eur J Cardiothorac Surg 2000; 17:530-537.

63. Reston JT, Shuhaiber JH. Meta-analysis of clinical outcomes of maze-related surgical procedures for medically refractory atrial fibrillation. Eur J Cardiothorac Surg 2005; 28:724-730.

64. Quader MA, McCarthy PM, Gillinov AM, Alster JM, Cosgrove DM, Lytle BW et al. Does preoperative atrial fibrillation reduce survival after coronary artery bypass grafting? Ann Thorac Surg 2004; 77:1514-22; discussion 1522. 